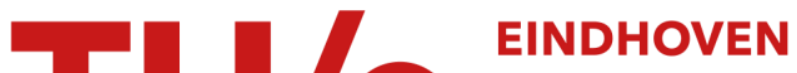 \\ UNIVERSITY OF \\ TECHNOLOGY
}

\section{Verbal protocol accuracy in fault diagnosis}

\author{
Citation for published version (APA): \\ Brinkman, J. A. (1992). Verbal protocol accuracy in fault diagnosis. (EUT - BDK report. Dept. of Industrial \\ Engineering and Management Science; Vol. 51). Technische Universiteit Eindhoven.
}

\section{Document status and date:}

Published: 01/01/1992

\section{Document Version:}

Publisher's PDF, also known as Version of Record (includes final page, issue and volume numbers)

\section{Please check the document version of this publication:}

- A submitted manuscript is the version of the article upon submission and before peer-review. There can be important differences between the submitted version and the official published version of record. People interested in the research are advised to contact the author for the final version of the publication, or visit the $\mathrm{DOI}$ to the publisher's website.

- The final author version and the galley proof are versions of the publication after peer review.

- The final published version features the final layout of the paper including the volume, issue and page numbers.

Link to publication

\section{General rights}

Copyright and moral rights for the publications made accessible in the public portal are retained by the authors and/or other copyright owners and it is a condition of accessing publications that users recognise and abide by the legal requirements associated with these rights.

- Users may download and print one copy of any publication from the public portal for the purpose of private study or research.

- You may not further distribute the material or use it for any profit-making activity or commercial gain

- You may freely distribute the URL identifying the publication in the public portal.

If the publication is distributed under the terms of Article 25fa of the Dutch Copyright Act, indicated by the "Taverne" license above, please follow below link for the End User Agreement:

www.tue.nl/taverne

Take down policy

If you believe that this document breaches copyright please contact us at:

openaccess@tue.nl

providing details and we will investigate your claim. 


\section{Eindhoven University of Technology Netherlands}

Department of Industrial Engineering and Management Science

\section{Verbal Protocol Accuracy in Fault Diagnosis}

by

J.A. Brinkman 
VERBAL PROTOCOL ACCURACY IN FAULT DIAGNOSIS

door

J.A. Brinkman

Report EUT/BDK/51

ISBN 90-386-0151-4

Eindhoven 1992

Eindhoven University of Technology

Graduate School of Industrial Engineering and Management Science

Eindhoven, Netherlands 


\section{CIP-GEGEVENS KONINKLIJKE BIBLIOTHEEK, DEN HAAG}

Brinkman, J.A.

Verbal protocol accuracy in fault diagnosis / door J.A. Brinkman

Eindhoven: Eindhoven University of Technology.

Department of Industrial Engineering and Management Science.

(Report EUT/BDK;51)

With references.

ISBN 90-386-0151-4

Subject headings: knowledge education, verbal protocol analysis, fault diagnosis. 


\title{
Verbal protocol accuracy in fault diagnosis'
}

\author{
Jan A. Brinkman
}

\begin{abstract}
The study reported here examined whether concurrent and retrospective verbal protocols possess the potential to provide a non-reactive and valid account of the cognitive processes involved in fault diagnosis. With this goal in mind, a group of subjects performed a fault diagnosis task under concurrent and retrospective verbalization and in a silent control condition as well. In the task, concurrent verbalization led to a considerable increase in time to completion but exerted no effect on overall accuracy and the adopted strategy. Retrospective verbalization did not have any effect on performance. The strategy-related data obtained under concurrent verbalization proved to be more valid than those obtained under retrospective verbalization. The implications of these results are discussed from a practical, theoretical, and methodological point of view.
\end{abstract}

'Portions of this report were first published in 1990 in the author's Ph.D. thesis "The analysis of fault diagnosis tasks: Do verbal reports speak for themselves?". The experimental results reported here differ in a number of respects from those reported in the thesis. This is because the data analyses are based on a partly different sample of subjects and the algorithm used for identifying the subjects' strategies has been simplified. These differences, however, are small and do not affect the conclusions drawn. 


\section{Introduction}

When the normal operation of a technical production system is allocated to a machine, the major task the human operator has to fulfill may become that of diagnosing faults. Various attempts have been made to assist the operator in performing this task adequately (see e.g. Rasmussen and Rouse, 1981). These include improving the information display of the system's state, supplying on-line computer aiding, and providing training through simulation, to mention a few. It is generally recognized that these attempts can only be successful if they are based on a thorough understanding of the cognitive processes the operator is engaged in while doing the task. One of the techniques which has frequently been adopted in the past and which use appears to be increasing in order to obtain such an understanding is the verbal protocol methodology. Generally speaking, this technique consists of inferring the cognitive processes used in a particular task from a subject's own verbal reports on these processes. This essentially involves having subjects overtly verbalize what they are or have been thinking during task performance. The verbalizations they produce are recorded and subsequently encoded, usually in terms of the task-directed processes supposedly referred to.

There are, however, a number of methodological questions to be raised against this technique. First, there is the question whether the verbal reports that are obtained suffer from reactivity and second, there is the question whether the reports are really valid. Reactivity occurs if the cognitive processes which normally proceed during task performance are changed by the mere requirement to verbalize them concurrently or retrospectively. For example, when there are several ways to do a task, it may be that verbalization has the effect that the normal way is changed for a way which is more easily described. When lacking validity, the reports do not accurately reflect the cognitive processes that actually go on, irrespective of the question whether the processing is reactive or not. For example, in a highly practised task, the speed of the ongoing processes may exceed the ability to verbalize them completely.

And yet, the general picture emerging from the empirical literature is that these problems are not as serious as one might think. This is at least the case when considering the studies in which 
verbalization procedures are adopted which may be qualified as adequate in the sense that they urge to report only about the information that is actually attended to during task performance. According to the foremost theory of verbal reporting currently available, i.e. model developed by Ericsson and Simon (1984), such procedures should be favorable to both forms of verbal report accuracy, i.e. nonreactivity and validity. It appears that a good many of these studies give no or hardly any indications of inaccuracies in verbal reporting. Specifically, in many cases, a near absence of reactivity in concurrent verbal reports is found. That is to say, concurrent verbalization does not seem to change the course and structure of task-directed processes, although it may decrease the processing speed somewhat (see e.g. Deffner, 1984 and 1989; Fidler, 1983; Rhenius and Deffner, 1990; Rhenius and Heydemann, 1984). And also, in some cases, retrospective verbal reports do not appear to suffer from any reactivity (e.g. Russo et al., 1989). In addition, the validity of concurrent verbal reports has in general been found to be satisfactory (Deffner, 1984, experiment 1; Heydemann, 1986; Mathews et al., 1988, experiment 1 and 2; Rhenius and Heydemann, 1984). Finally, there is suggestive evidence that the validity of retrospective verbal reports can be brought up to an acceptable level when adequate recall aids are presented (Bowers and Snyder, 1990; Hoc and Leplat, 1983). Results like these suggest the conclusion that the verbal protocol methodology is a viable research tool for analyzing the cognitive processes involved in the task of fault diagnosis. Unfortunately, the evidence provided by the studies conducted so far is associated with several difficulties as a result of which we are not entitled to draw such a strong conclusion.

First, the available empirical evidence is relatively modest. While a good deal of research has been designed to investigate the reactivity of concurrent verbal reports, we know of a relatively small number of studies focussing on the validity of this type of report. And to our knowledge, there are hardly any studies on the reactivity and the validity of retrospective verbal reports.

Second, the tasks commonly employed in the studies are rather artificial. For example, they consist of items drawn from traditional psychological tests like Raven's Progressive Matrices. Only a couple of studies cover more realistic task domains. Notable exceptions are the managerial decision task used by Schweiger (1983), the windowing 
benchmark task used by Bowers and Snyder (1990), and the dynamic systems control task employed by Berry and Broadbent (1984), McGeorge and Burton (1989), and Stanley et al. (1989). As far as we know, there is as yet no empirical study testing the accuracy of verbal reporting in a typical fault diagnosis setting.

Third, several studies yield data which indicate more or less strong deviations form accurate verbal reporting. Notably, there are a number of instances where substantial reactivity in concurrent and in retrospective verbal reports has been observed (see e.g. Biehal and Chakravarti, 1989; MCGeorge and Burton, 1989, experiment 1; Russo et al., 1989; Stanley et al., 1989, experiment 1). In these cases, the task-directed processes seem to change fundamentally because of the requirement to verbalize them concurrently or retrospectively. In addition, it appears that the tasks taking more time to perform when concurrent verbalization is asked for are quite diverse (see e.g. Deffner, 1984; Rhenius and Deffner, 1990). Thus, the generation of a concurrent verbal report seems to exert a general slowing down effect on task-directed processes. Furthermore, there is evidence to suggest that the validity of retrospective verbal reports may be inferior to that of concurrent reports (Fidler, 1983; Russo et al., 1989).

Fourth, many studies suffer from methodological imperfections which threaten the validity and/or generality of the conclusions drawn (see Brinkman, in press). The approach usually followed to provide an empirical assessment of verbal report accuracy consists of testing for reactivity by comparing a set of performance data which have been collected in a verbalization condition with a similar set of data from an associated silent control condition. It also consists of testing for validity by relating a set of protocol data to a set of performance data, both collected in a verbalization condition. The lower the agreement between the two sets of measures being compared, the more reactive or the more valid the verbal reporting is assumed to be. When adopting this approach, threats to validity may stem from failures to verify whether the collected data fulfill the assumptions underlying the tests performed. The three basic assumptions being made pertain to: (1) the validity of the performance data, (2) the reliability of the protocol data, and (3) the sensitivity of the two sets of data. Moreover, it is assumed that the adopted verbalization procedures are more or less effective in tapping the cognitive processes under study. Threats to generality are typically due to the 
following two limitations: (1) testing only one of the two forms of verbal report accuracy, i.e. either reactivity or invalidity, and (2) using data capturing only the outcomes of the cognitive processes engaged in, such as total time on task and overall accuracy. On the one hand, each of these two limitations can have the effect that true deviations from verbal report accuracy go unnoticed. With the first restriction this is because of the possibility that accuracy in the tested form is achieved at the cost of accuracy in the not-tested form. With the second restriction this is by virtue of the fact that exactly the same outcome of a cognitive process may be generated through entirely different underlying operations, e.g. there may be a variety of strategies to complete the task to be done. On the other hand, the two limitations can also lead to the erroneous conclusion that an accurate verbal report cannot possibly be realized, the first restriction because of the possibility that inaccuracy in the tested form is simply caused by inaccuracy in the not-tested form, and the second restriction by virtue of the fact that verbal report inaccuracy may affect the outcomes of a cognitive process but not the operations. To sum up, given the current state of empirical evidence, it is premature to conclude that the verbal protocol methodology can indiscriminately be applied as a veridical way of studying the fault diagnosis process. Therefore, the present study has been designed to provide more direct evidence with respect to this issue. More specifically, it is concerned with the reactivity and validity of concurrent and retrospective verbal reports on fault diagnosis. The approach followed tries to eliminate a number of the methodological problems associated with many of the previously conducted studies on verbal report accuracy.

\section{Method}

This section describes the way in which in the study the performance data and the protocol data needed for assessing verbal report accuracy were gathered.

\subsection{Collecting performance data}

\section{$\underline{\text { Task }}$}


Based on a search of the relevant literature, it was decided to use the fault diagnosis task developed by Rouse (1978). The following two considerations guided the choice of this task. First, the task of Rouse possesses a certain degree of ecological validity. It incorporates at least some of the critical features of diagnosis situations faced by human operators in real life. Second, the task of Rouse seemed to have the potential to infer a subject's strategy from his observable behaviors. This would make it possible to test for strong deviations from verbal report accuracy to occur. By this is meant a form of reactivity where reporting about the task being done induces a strategy differing from the one normally adopted. As to invalidity, it implies a form where the verbal report produced does not adequately indicate the strategy actually adopted.

The task of Rouse requires fault finding in graphically displayed networks which consist of $\mathrm{N}$ rows and $\mathrm{N}$ columns of interconnected logical AND-gate components (Fig. 1). In each network, one randomly

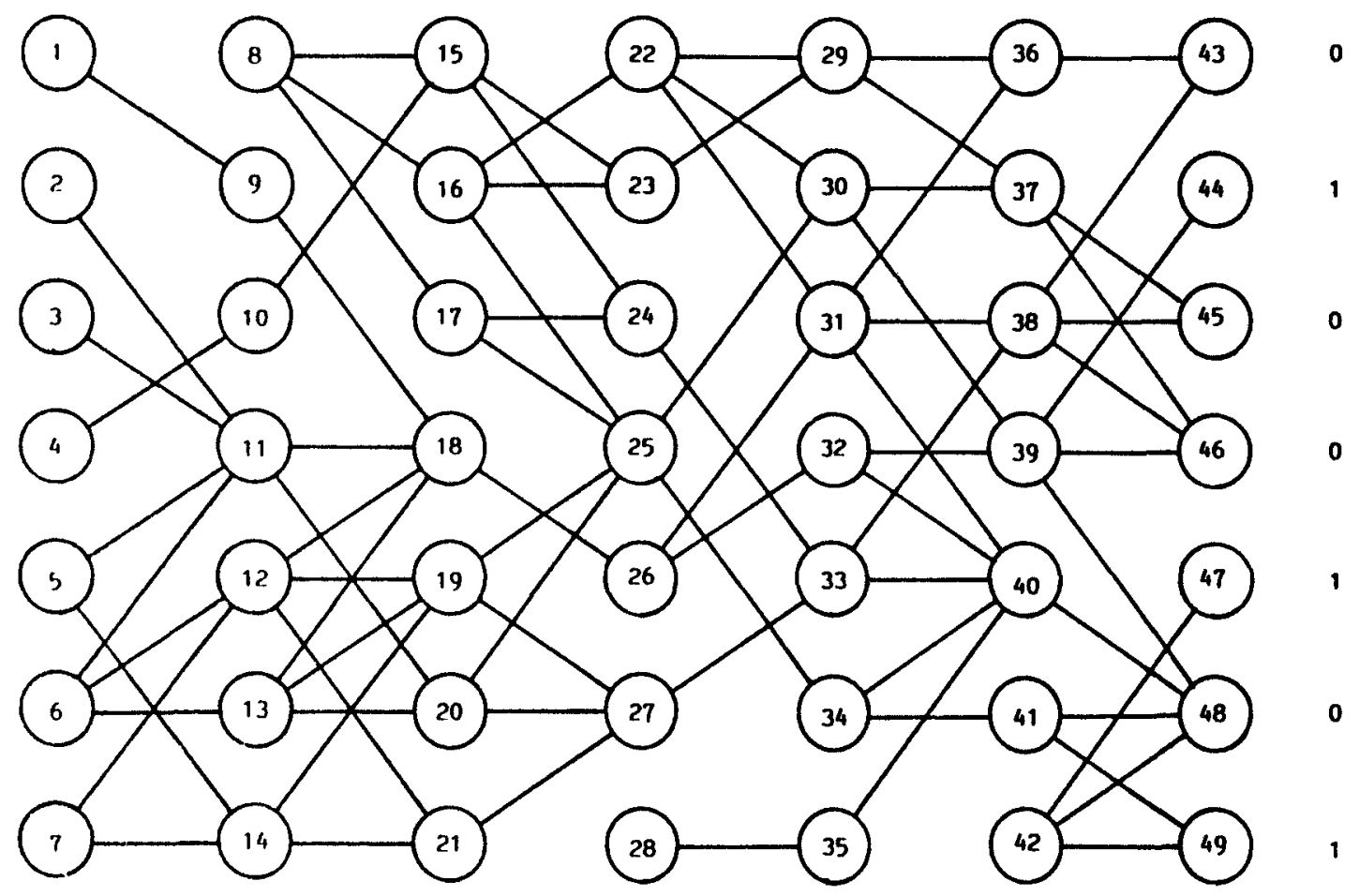

Figure 1. Example of a network with outputs. Component 21 is faulty. 
selected component is the faulty one and it is the task of the subject to locate this component. The subject can achieve this by interpreting the outputs of the network and by testing connections and components within the network. Having made a test, the subject receives its value unless he tests the faulty component in which case the problem has been solved. Connections and components are tested in successive trials where a test on a connection counts for one trial and a test on a component for three trials (Fig. 2). For a more complete description of the task, see Rouse (1978).

\section{trial 1: 31.38 status connection 1 trial 2: 24.33 status connection 1 trial 3: 27,33 status connection 0 trial 4: $\frac{27}{21}$ status component 0 trial 7: 21.27 status connection 0 trial 8: 21 !! correct!!}

Figure 2. Example of a series of connections and components tested by a subject during the fault diagnosis task. The subject diagnosed the network presented in Fig. 1. The tests he made have been underlined.

\section{Strategies}

By combining the results of normative modelling attempts presented in the literature (Rouse, 1978) with an analysis of verbal reports obtained in a pilot experiment, we identified for the fault diagnosis task two basıcally distinct strategies, referred to as tracing-back (TB) and hypothesis-and-test (HT). Morrison and Duncan (1988) have identified two similar strategies for the task. In the following, these strategies are described from a more "logical" and a more "psychological" point of view.

Logical strategy description. When employing the TB strategy, the subject first selects as a starting-point an arbitrary component from the set of components with a known value of 0 . Next, he chooses an arbitrary input of this component and tests its value. If the input gets the value of 1 , he will then test another input of the component. If, on the other hand, the input becomes 0 , he will then select as a new starting-point the component from which the tested input leaves. The subject repeats this procedure until he finds a component of which 
none of the inputs gets the value of 0 . The component to which this applies is the faulty one.

In the HT strategy, the subject identifies one or more of the components that could have failed, given the information acquired so far. The subject derives this set of possibly faulty components by determining what components connect directly or indirectly to all components with a known value of 0 and do not connect to any component with a known value of 1 . For instance, in the network problem given in Fig. 1 the complete set of possibly faulty components prior to testing consists of $4,10,15,21,24,27,31$, and 33. From the derived set, the subject selects one or more components as a basis for performing tests. If (one of) the selected component(s) does not appear to be the faulty one, the subject adjusts the set by eliminating those components which, on the basis of the test result, can be ruled out as possibly faulty. Once the set of possibly faulty components has been reduced so as to contain only one feasible component, this should be the faulty one.

When comparing these two basic strategies, it appears that they differ in the extent to which at any particular moment use is made of the available information. As will be evident from the preceding, the amount of information utilized is larger when adopting the HT strategy than the TB strategy. It thus seems appropriate to qualify HT as more thorough than TB.

The basic strategies should be regarded as idealized ways of performing the task. It is not to be expected that a particular subject will conform entirely to one of these. That is to say, one should allow for the possibility that a given subject may adopt a working-style which differs in one or more respects from the strategies identified here. When this occurs, the subject is said to follow an indefinite (IN) strategy. And also, the subject, while doing the task, may shift from one working-style to another. Nevertheless, the postulated strategies will most likely be quite similar to those used by many of the subjects.

Psychological strategy description. The strategies described above seem to place different loads on the cognitive processes involved. Consider first the processing requirements of the TB strategy. At any time during this strategy, the perceptual field is restricted in that the attention is always directed towards only one particular component and its adjacent inputs. The strategy will therefore involve no 
extensive visual search. Furthermore, the algorithm used (i.e. test the inputs of a component the output of which has just been found to be 0$)$ is that simple that the mental calculations engaged in are limited and the memory load involved is low. The processing requirements of the HT strategy differ considerably hereof. This strategy appears to depend heavily on pattern recognition and complex reasoning because of the requirement to derive throughout the network components that can or cannot fail. Since a more or less permanent record of these components is further required, the strategy also imposes a considerable load on memory.

In sum, the amount of cognitive effort required by the task is larger when adopting the HT strategy than the TB strategy.

Differences in the processing requirements of the distinct strategies will manifest themselves as differences in observable task behaviors. Specifically, during the TB strategy, a rapid sequence of tests is carried out and no attention is paid to whether each individual test is redundant or not. So, if this strategy is used, the tests are made quickly after another, but many are needed to find the fault. In the HT strategy, on the other hand, each test being made is informative and the result of careful and time-consuming information processing. Thus, when employing this strategy, the fault is found in a few number of tests, although each test takes a considerable amount of time.

\section{Subjects and design}

Eighteen subjects from the Eindhoven University of Technology participated in the study. They were paid on an hourly basis.

The variable of primary interest was verbalization type which consisted of three levels: (1) no verbalization, (2) concurrent verbalization, and (3) retrospective verbalization. This variable was introduced as a within-subjects factor. By doing this, the sensitivity needed for detecting verbalization effects was likely to increase since it is reasonable to assume that in a relatively complex task as the task of Rouse random performance variability within a subject will be substantially less than between subjects. To control for possible order effects among the different levels of verbalization type, a subject received these levels first in the order 123 and then in the reversed order, i.e. 321 . Here, the consecutive numbers in a sequence refer to the successively administered levels of 
verbalization type with each verbalization administration comprising two experimental problems to be solved. In a previous study, order of verbalization type was experimentally manipulated as well, but this variable did not show any systematic performance effects. This indicates that the present design did not risk undesirable asymmetric transfer effects from one level of verbalization type to another.

In order to test the sensitivity of the data, task difficulty was also manipulated. This variable was a within-subjects factor with four levels. Each subject had to solve the same set of 12 experimental problems. This set was randomly split up into three subsets, though subject to the constraint that each verbalization type contained four problems each of which represented another difficulty level. In other words, verbalization type constituted a factorial combination with task difficulty. The subsets were assigned to the different levels of verbalization type according to three distinct ways, which, taken together constituted a Latin square. By doing this, it was accomplished that the different subsets were counterbalanced over verbalization type. Each subject was randomly allocated to one of the three ways of problem assignment with the constraint that each way involved six subjects.

\section{Instructions}

Two sets of written instructions were prepared, in particular a task and a verbalization instruction.

Task instruction. This instruction explained the nature of the fault diagnosis task and the use of the computer terminal. It also described the two basic strategies of the task although the subject was left free to follow the strategy he preferred. The subject was further instructed to complete the task in a minimum of test trials and at his own pace. So, accuracy rather than speed was stressed. Four paper and pencil exercises were added to the task instruction for the purpose of testing the subject's understanding of the task.

Verbalization instruction. The verbalization instruction was adapted from Ericsson and Simon (1984). Specifically, the instruction given for concurrent verbalization asked the subject to think aloud while doing the task. Thinking aloud was explained to the subject as telling everything he was thinking of from the moment the task began till its end. The instruction encouraged him to talk aloud constantly but dissuaded him from planning beforehand what to say and from explaining 
what he said. For retrospective verbalization, the instruction asked the subject to tell everything he could remember about what he was thinking when he performed the task. In this instruction, the subject was requested to report what he actually could remember about his thoughts, preferably in the sequence in which they occurred, rather than what he supposed to must have thought. When uncertain about his memories, he could tell this to the experimenter. The instruction also encouraged him to make use of the recall aid given (see below).

\section{Stimulus materials}

Sixteen problems to be administered by a computer were developed. Twelve of these served experimental purposes while the remaining four were used for practice. For each problem, the computer generated a different network. One of the networks had a small size consisting of 25 components arranged in a matrix of 5 rows and 5 columns. This network was used in the first practice problem. The other networks were large, consisting of 49 components arranged in a matrix of 7 rows and 7 columns. For each problem to be presented, the faulty component was selected at random, with the exception that the output components of the network could not fail. The selection was performed without replacement. The subjects were not informed of this.

In order to generate problems which varied in difficulty, an adequate dimension of task difficulty was needed. On the basis of the relevant literature (Rouse and Rouse, 1979) and a pilot experiment, it was assumed that in the fault diagnosis task used the dimension "number of components that possibly fail before any tests are made" would be effective. That is to say, a problem was conceived of as being more difficult if its initial set of possibly faulty components was larger. Based on this assumption, the problems to be presented were generated so that they differed with respect to the initial feasible fault set. In the experimental problems, this set took one of four possible sizes. It consisted of $8,11,14$ or 17 components. Thus, in the experiment, four different levels of task difficulty were employed. Of the experimental problems, there were always three having the same initial feasible set size. The initial feasible set size of each practice problem was 8 . 


\section{Apparatus}

A subject was tested in isolation in a sound-attenuated room in which he sat in front of a graphical display unit located at his left hand and a terminal consisting of a text display with a keyboard attached to it at his right. Both devices were driven by a computer which was programmed to control the fault diagnosis task to be performed by the subject. During the experiment, the subject was under supervision of the experimenter who sat in a room next to the test room. The communication between subject and experimenter proceeded through an intercom system. A complete record was made of the subject's verbalizations by hanging a microphone around his neck and connecting it to a tape-recorder in the experimenter's room.

\section{Procedure}

A subject took part in one experimental session which consisted of a practice and an experimental phase.

Practice phase. In this phase, the subject first studied the task and verbalization instruction. Then, he made the four paper and pencil exercises added to the task instruction. Upon completion of the exercises, he received feedback about his performance. Thereupon, the subject solved the four computer-administered practice problems. The first two problems had to be done in silence, the third problem required concurrent verbalization and the last one retrospective verbalization. The practice phase took on the average approximately one hour.

Experimental phase. In this phase, the subject solved the 12 computeradministered experimental problems. At the start of each problem, the text display showed the particular verbalization type required. This request remained on the display for the time the subject solved the problem administered. The experimenter saw to it that the subject obeyed to this. That is to say, when concurrent verbalization was asked for and the subject lapsed into silence for more than about 10 sec., the experimenter would persuade him to resume verbalization. Conversely, when no verbalization or retrospective verbalization was requested and the subject did start verbalizing during the problem, the experimenter would urge him to be silent. During each problem, the visual display unit showed the network in which the subject had to locate the faulty component. As soon as on the text display the current trial number appeared, the subject could perform a test by 
activating the keyboard. Having entered the desired test, the computer would present the appropriate information on the display. Subjectcomputer interactions recorded in previous trials were not erased from the display. When the subject upon completion of a problem had to report retrospectively, the network as well as the record of the dialogue remained available. He could use this problem-specific information as an aid to recall his previous thoughts. In the experimental phase, the subject was never allowed to use paper and pencil. The experimental phase lasted on the average about two hours.

\section{Performance measures}

Several product- and operation-oriented measures were utilized to describe the subject's performance in each problem he solved. To capture time-related aspects of performance the following productoriented measure was included: the time taken to complete a problem. Performance accuracy was captured by the product-oriented measure the number of test trials needed. The operation-oriented measures being used were meant to describe the adopted diagnostic strategy. An algorithm was developed to infer from the tests the subject made the particular strategy he followed. This algorithm, which is described fully in the Appendix, should be seen as an attempt to cast the logical strategy specifications into a set of definitions and rules which can be applied to a concrete test situation. The algorithm tried to classify each test into one of the two basic strategies. The test on the faulty component was not encoded unless it was the first one. If a particular test fulfilled neither strategy, it would be classified as indefinite. Such a classification should not be considered as a failure of the algorithm since it was in principle possible that a subject followed a strategy which differed from the two basic strategies. If the algorithm did fail, that is to say, if a given test fulfilled both strategies, it would receive the classification undefined. In order to guarantee an objective identification of the strategies, a computer implementation of the algorithm was realized. The following three measures were constructed from the strategy classifications the algorithm produced: the proportion of TB, the proportion of HT, and the proportion of IN. Each proportion was expressed as a percentage of the total number of tests performed, the test on the faulty component and the tests classified as undefined excepted. 
The validity of the strategy-related performance data was verified using the measure the time taken per test attempted. To test the effectiveness of the chosen dimension of task difficulty, the deviation from the statistically optimal strategy was determined. This measure was calculated by subtracting the number of trials a subject needed to solve a problem from the number of trials needed for solving the problem when adopting the split-half algorithm (Rouse, 1978).

\subsection{Collecting protocol data}

\section{Coders}

Six subjects who had previously participated in the experiment served as coders. They were paid per hour. The coders were randomly divided into two groups of equal size. Hereafter, the groups will be referred to as group 1 and 2 .

\section{Coding materials}

Transcriptions were made of all the tape-recorded verbal protocols coming from a total number of 15 subjects. One or more protocols from each of the three remaining subjects could not be transcribed due to failures of the recording apparatus or because of poor tape-recording quality. These subjects were excluded from the protocol-based analyses described below.

Since the analysis of a verbal protocol may be rather laborious, it was decided to have each coder analyze only a portion of all the verbal protocols being transcribed. For this purpose, two sets of protocol transcriptions were selected. Each set consisted of the protocols from a completely different group of six subjects. All the protocols which these subjects generated in the experimental phase (i.e. per subject four concurrent and four retrospective reports) were included. Thus, a set was made up of a total number of six (subjects) times eight (protocols per subject) is 48 protocols. Each coder of group 1 received one set and each coder of group 2 the other.

The order in which the selected verbal protocols were presented was randomized for each coder. This was done to reduce the possibility that the coder, while analyzing a subject's verbalizations contained in the current protocol, would infer from a preceding protocol what the subject might have been thinking. 
To determine intra-coder agreement, each coder would analyze eight protocols twice. These protocols were randomly selected from the first half of the protocols contained in the original set and administered to the coder at first. The selection was restricted to the first half in order to reduce the possibility that the coder would use his specific memories of previous protocol encodings when analyzing the same protocol once again.

\section{Coding instructions}

A written instruction was prepared containing detailed information being essential for the task of analyzing verbal protocols. In the first part of this instruction, a complete description was given of the different fault diagnosis strategies together with typical examples. This part essentially consisted of the logical strategy specification presented above. No reference was made to the psychological implications of the strategies. The second part described at great length the standardized way in which the verbal protocols were to be encoded into these strategies. This part in particular consisted of five examples of carefully encoded protocols.

In analyzing a protocol, the coder was instructed to proceed according to the following two steps. First, he had to derive which diagnostic tests the subject successively made. Then, he had to encode each test, with the exception of the one performed on the faulty component, into one of the distinct strategies. The coding categories to be used were: TB, HT, and IN. The coder was emphatically stimulated to base his strategy classifications on the subject's overt verbalizations rather than on plausible inferences as to what the subject might have been thinking.

Another series of five verbal protocols was compiled for the purpose of providing the coder with concrete practice in protocol analysis. In an additional set of papers, these protocols were encoded in a way as outlined in the instruction. This set would serve feedback purposes.

\section{Coding procedure}

A coder took part in five or six sessions each of which lasted about three hours. In each session, the coder worked individually and at his own pace. In the first two sessions, the coder received extensive training in protocol analysis. In order to refresh his memories, he 
first read again the instruction of the fault diagnosis task and then once more solved a number of computer-administered diagnostic problems. Thereupon, he studied the instructions describing the task of protocol analysis. He indicated when he had completed this instruction and then encoded the verbal protocols that made up the practice set. After having finished this work, he was given the set of papers describing the correct protocol encodings with which he was to compare the encodings he had made. Whenever he observed differences in it, he would discuss these with the experimenter to find the source. From the third session on, the coder worked through the set of verbal protocols selected to be analyzed.

\section{Protocol measures}

Differences between the coders in the strategy encoding given to a particular test were resolved by applying a majority principle. That is to say, the encoding selected for further analysis was always the one given by at least two of the three coders making up a group. If there was no majority for one of the strategies, the encoding indefinite would be used. The protocol-based encodings thus obtained were utilized to derive the same strategy-related measures as those derived from the classifications made by the computer algorithm. In addition, for each protocol being transcribed, the frequency of verbalization (defined as the number of words spoken per test) was determined. For each transcribed concurrent protocol, the rate of verbalization (defined as the number of words spoken per minute) was calculated as well.

\section{Results}

Apart from simple correlation analyses, the major statistical technique used was analysis of variance. Because of our interest in detecting measure-specific verbalization effects, it was decided to apply for each measure defined above a multivariate repeated measurement model (MANOVA). Thus, the data were not treated as multivariate with respect to scores on several measures but they were with respect to repeated scores on one measure. In the analyses, we did not want to overlook small, though true verbalization effects. It was therefore considered advisable to increase the level of alpha from the conventional value of 0.05 to 0.10 . That is to say, all those 
effects of verbalization type of which the p-value came up to 0.10 would be examined more closely. Nevertheless, only if a given $p$ exceeded the 0.05 level would the corresponding effect be regarded as statistically significant.

The first step in the analyses was to verify whether the data fulfilled the assumptions underlying the tests of verbal report accuracy (3.1). After having established that this seemed to be the case, the required tests were carried out (3.2).

\subsection{Checks on assumptions}

\section{Validity of performance data}

Validation was needed of the strategy classifications the computer algorithm generated on the basis of the tests the subjects made during the task. This was realized by examining whether these classifications were associated with behavioral differences in a way which corresponded with the psychological strategy description of the task. For this purpose, the two algorithm-based measures the proportion of TB and the proportion of HT were correlated with the two measures the time taken per test and the number of trials. Since the relationships to be examined were expected to occur in any problem, the correlation analysis was carried out by averaging the data across all the 12 experimental problems. Allowing for the possibility that the relationships were not linear but took the form of some monotonic function, Spearman's rank correlation coefficient $r_{s}$ (one-tailed) was applied. The results were as follows. The proportion of TB correlated negatively with the time taken per test $\left(r_{s}=-.35, p=0.078\right)$ and positively with the number of trials $\left(r_{s}=0.55, p=0.009\right)$. The proportion of HT, on the other hand, correlated positively with the time taken per test $\left(r_{s}=0.63, p=0.002\right)$ and negatively with the number of trials $\left(r_{s}=-0.67, p=0.001\right)$. It thus appears that three of the four correlation coefficients were significant and at least of moderate size whereas the fourth one approached significance and had a somewhat smaller size. Furthermore, all the coefficients appear to present trends in accordance with the relationships specified by the task's psychological strategy description. The coefficients essentially point out that the higher the proportion of TB, the shorter the time taken per test and the larger the number of trials, and also, the higher the proportion of HT the longer the time taken per test and the smaller 
the number of trials. In conclusion, the results supported the validity of the algorithm developed for identifying the subject's strategies.

\section{Reliability of protocol data}

The reliability of the protocol data was evaluated by determining inter- and intra-coder agreement.

Inter-coder agreement. Inter-coder agreement was determined by calculating for each pair of coders from the two groups involved the correspondence between the strategy encodings extracted from the concurrent and retrospective verbal protocols. To measure the degree of this correspondence, Cohen's kappa (Cohen, 1960) was employed. This measure gives the proportion of agreement after chance agreement has been removed from consideration. Across all pairs of coders, kappa ranged for the concurrent verbalization encodings from 0.57 to 0.85 with a mean of 0.75 (N varied from 132 to 136 with a mean of 133.83). Likewise, kappa ranged for the retrospective verbalization encodings from 0.48 to 0.72 with a mean of 0.64 (N varied from 99 to 109 with a mean of 104.33). The mean kappa's indicate that for both types of protocol encoding the inter-coder agreement was on the average substantial. Note that the mean kappa based on the concurrent verbalization encodings was somewhat higher than the kappa of the retrospective verbalization encodings.

Intra-coder agreement. Intra-coder agreement was determined by computing the correspondence between the strategy encodings a coder extracted from the protocols presented to him twice. Since the number of these protocols, i.e. eight, was too small to this accurately for the concurrent and retrospective encodings separately, all the encodings were combined per coder to provide one index of intra-coder agreement. Across all coders, kappa measure ranged from 0.63 to 0.95 with a mean of 0.77 ( $\mathrm{N}$ varied from 32 to 59 with a mean of 40.50 ). Each coder gave a kappa in excess of 0.60 . These figures point that on the average and for all individual coders intra-coder agreement was quite substantial.

\section{Sensitivity of performance data and protocol data}

A preliminary analysis was carried out to check whether the dimension of task difficulty used was appropriate in the sense of producing a deterioration of performance with an increase in problem difficulty. 
The performance measure used for this purpose was the deviation from optimality. On this measure, the mean scores were calculated for each level of task difficulty. These calculations were carried out across the different levels of verbalization type. An inspection of the resulting means unfortunately revealed that an increase in task difficulty failed to produce a steady performance degradation. For example, the lowest level of task difficulty appeared to be associated with the worse rather than the best performance. This result might seriously hamper the interpretation of the task difficulty effects. It was therefore decided to recode the different levels of the difficulty factor so that a higher level would be associated with a worse performance.

As described in the method section, the experimental problems were administered in three sets of four problems each. This was done so that for each way of problem presentation one set was meant for another verbalization type. So, in order to maintain a factorial combination between verbalization type and task difficulty, the recoding was carried out within each set of problems. The performance measure used for this purpose was the deviation from optimality. The recoding then was accomplished by calculating the mean scores of the four problems making up the same set. These calculations were carried out across the different levels of verbalization type. Based on the means obtained, the two problems of a set resulting in the best performance were designated as "easy" whereas the two other problems of that set were designated as "difficult". Thus, within each set, there were two experimental problems with the same designation of task difficulty. A subject's scores on any two such problems were averaged before being used in the subsequent analyses. These analyses, which are described more fully in the following section, showed that task difficulty as redefined above exerted the expected effects on practically all the performance measures included. This indicates that these measures possessed sufficient sensitivity. Furthermore, a number of measures, in particular those derived from the protocol encodings, revealed more or less pronounced effects of verbalization type. This may also be seen to indicate that the sensitivity requirement was met.

\section{Adequacy of verbalization procedures}

To get some indication of how effective the procedures used to verbalize were, it was also examined whether the generated verbal 
reports contained a satisfactory number of verbalizations. This was done by analyzing the frequency and the rate of verbalization.

Verbalization frequency. For the easy problems, the mean frequency of concurrent verbalization was 73.20 words per test with a standard deviation of 47.73 . For the difficult problems, the mean of this measure was 75.61 words per test with a standard deviation of 67.19 Retrospective verbalization had a mean frequency of 52.34 words per test with a standard deviation of 35.40 for the easy problems and had a mean frequency of 43.64 words per test with a standard deviation of 25.57 for the difficult problems. The mean figures suggest that the number of verbalizations contained in a concurrent or retrospective verbal report was on the average sufficiently large to be used as a basis for encoding each individual test.

The data on verbalization frequency were further analyzed by subjecting them to a two within-subjects MANOVA which included the factors verbalization type (i.e. concurrent versus retrospective with silence dropped) and task difficulty. In this analysis, the main effect of verbalization type proved to be significant $[F(1,14)=12.52$, $p=0.003)$. There was no significant main effect of task difficulty and no significant interaction between the two factors. The means given above show that, at both levels of task difficulty, the frequency of concurrent verbalization was higher than of retrospective verbalization.

Verbalization rate. For the easy problems, the rate of verbalization had a mean of 97.53 words per minute with a standard deviation of 32.43. For the difficult problems, this measure had a mean of 100.31 words per minute with a standard deviation of 24.34. The verbalization rates obtained here are close to those reported in the literature (see e.g. Ericsson and Simon, 1984) and can be considered to indicate that the subjects were able to produce a more or less steady stream of verbalizations. Note that the mean verbalization rate was somewhat lower for the easy than for the difficult problems, but a pairedsamples t-test revealed that this difference was not significant.

To conclude, the data showed no marked departures from the assumptions being made when testing verbal report accuracy. 


\subsection{Tests of verbal report accuracy}

\section{Verbal report reactivity}

Reactivity was tested by comparing the performance data collected in the concurrent and retrospective verbalization condition with the same type of data from the silent control condition.

Effects of verbalization type. Table 1 presents per verbalization type

Table 1. Mean and standard deviation for each performance measure per verbalization type and task difficulty. The mean is given at the top of a cell and the corresponding standard deviation at the bottom. Each proportion has been expressed as a
percentage.

\begin{tabular}{|c|c|c|c|c|c|c|}
\hline \multirow{3}{*}{$\begin{array}{l}\text { Performance } \\
\text { measure }\end{array}$} & \multicolumn{5}{|c|}{ Verbalization type } & pective \\
\hline & & & Task & lifficulty & & \\
\hline & Easy & Difficult & Easy & Difficult & Easy & Difficult \\
\hline $\begin{array}{l}\text { Time to completion } \\
\text { (in seconds) }\end{array}$ & $\begin{array}{l}191.24 \\
129.70\end{array}$ & $\begin{array}{l}216.15 \\
122.04\end{array}$ & $\begin{array}{l}224.55 \\
132.14\end{array}$ & $\begin{array}{l}254.08 \\
130.76\end{array}$ & $\begin{array}{l}210.22 \\
148.65\end{array}$ & $\begin{array}{l}195.80 \\
100.61\end{array}$ \\
\hline $\begin{array}{l}\text { Number of } \\
\text { trials }\end{array}$ & $\begin{array}{l}5.03 \\
1.45\end{array}$ & $\begin{array}{l}6.75 \\
2.26\end{array}$ & $\begin{array}{l}5.50 \\
2.36\end{array}$ & $\begin{array}{l}6.72 \\
2.12\end{array}$ & $\begin{array}{l}5.78 \\
1.97\end{array}$ & $\begin{array}{l}6.81 \\
1.86\end{array}$ \\
\hline $\begin{array}{l}\text { Proportion of } \\
\text { tracing-back }\end{array}$ & $\begin{array}{l}3.43 \\
7.24\end{array}$ & $\begin{array}{l}14.31 \\
21.58\end{array}$ & $\begin{array}{r}5.92 \\
13.25\end{array}$ & $\begin{array}{l}16.32 \\
19.41\end{array}$ & $\begin{array}{r}8.05 \\
13.69\end{array}$ & $\begin{array}{l}16.60 \\
15.87\end{array}$ \\
\hline $\begin{array}{l}\text { Proportion of } \\
\text { hypothesis-and-test }\end{array}$ & $\begin{array}{l}62.59 \\
30.55\end{array}$ & $\begin{array}{l}41.08 \\
25.36\end{array}$ & $\begin{array}{l}63.79 \\
34.46\end{array}$ & $\begin{array}{l}42.16 \\
32.67\end{array}$ & $\begin{array}{l}55.71 \\
31.04\end{array}$ & $\begin{array}{l}33.85 \\
32.48\end{array}$ \\
\hline $\begin{array}{l}\text { Proportion of } \\
\text { indefinite }\end{array}$ & $\begin{array}{l}33.98 \\
28.25\end{array}$ & $\begin{array}{l}44.61 \\
27.90\end{array}$ & $\begin{array}{l}30.28 \\
29.25\end{array}$ & $\begin{array}{l}41.52 \\
25.55\end{array}$ & $\begin{array}{l}36.25 \\
28.15\end{array}$ & $\begin{array}{l}49.55 \\
27.10\end{array}$ \\
\hline
\end{tabular}

and level of task difficulty the mean and standard deviation of all the performance measures to be evaluated. For each of these measures, a separate MANOVA was carried out which included the two withinsubjects factors verbalization type and task difficulty. In the MANOVA's, a priori contrasts were chosen so as to compare each of the two forms of verbalization, concurrent and retrospective, with the silent control. This was done for all the main and interaction effects 
involving verbalization type. The results showed that on all the performance measures referring to accuracy and strategy use neither form of verbalization yielded a $p<0.10$, i.e. either as main effect or in interaction with task difficulty. The only measure being affected was time to completion where the main effect of concurrent verbalization reached significance $[F(1,17)=5.25, p=0.035]$. When inspecting the means of this measure presented in Table 1 , it appears that more time was needed to complete the task under concurrent verbalization than in silence. This is also illustrated in Fig. 3 where the means are plotted.

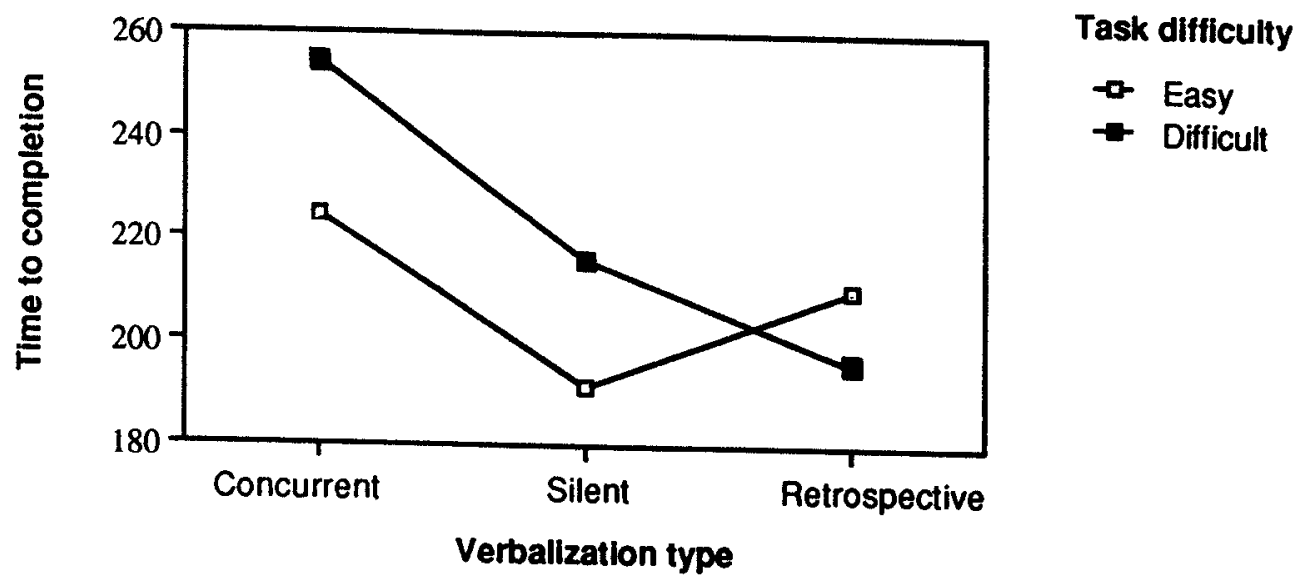

Figure 3. Mean time to completion (in sec.) for each verbalization type as a function of task difficulty.

other effects. The results also showed that for practically all the performance included, there was a significant main effect of task difficulty. The measures being affected were: the number of trials $[F(1,17)=34.55, p=0.000]$, the proportion of $T B[F(1,17)=22.51$, $p=0.000]$, the proportion of $\operatorname{HT}[F(1,17)=17.45, p=0.001]$, and the proportion of $\operatorname{IN}[F(1,17)=5.43, p=0.032]$. From an inspection of the means presented in Table 1 it is apparent that for each of these measures task performance on the easy problens was more accurate and more thorough than on the difficult problems. The only measure revealing no significant effect of task difficulty was time to completion. The failure to find such an effect for this measure seemed (in part) to be due to retrospective verbalization where, in contrast 
to the two other conditions, it took longer to complete the easy problems than the difficult problems (see Table 1 or Fig. 3). Strategy-dependent effects of verbalization type. A further correlation analysis was carried out to examine the possibility suggested by Deffner (1989) that effects of concurrent verbalization on time-related aspects of performance may depend on the strategy adopted. Specifically, within the concurrent verbalization condition, the proportion of TB and the proportion of HT were correlated with the proportional increase in the time taken to complete the task relative to the silent control condition. Note that the increase in the time to task completion from concurrent verbalization to silence was not calculated absolutely but expressed as a percentage. This was done to control for the possibility that with a longer time on task more time might be needed for verbalization. Furthermore, to control for subject differences and effects of task difficulty, the difference between the two conditions in the time to task completion was carried out within each subject at each of the two levels of task difficulty. It appeared that the proportion of TB correlated positively with the time on task relative to silence $\left(r_{s}=0.42, p=0.080\right.$, two-tailed $)$ while the proportion of HT correlated negatively with this measure $\left(r_{s}=-0.67, p=0.002\right.$, twotailed). Thus the two coefficients were (marginally) significant and at least of moderate size, and they indicated an opposite direction. However, one should allow for the possibility that these correlations were confounded by one or more uncontrolled variables which in some way or another obscured the actual relationships. One of the most obvious variables possibly exerting such an effect is the ability to verbalize the cognitive processes engaged in (see also Deffner et al., 1987). It was therefore decided to correlate within the concurrent verbalization condition the two strategy-related performance measures also with the rate of verbalization. In this analysis, one-tailed tests were carried out since the question to be answered implied a directional hypothesis. It appeared that neither correlation coefficient approached significance. This suggests that the rate of verbalization did not vary with the strategy adopted. So, the observed relationships between strategy use and increase in time on task with concurrent verbalization did not seem to be due to strategy-dependent differences in verbalization rate.

It should be realized that the correlation analyses reported here were carried out by averaging the data across the two levels of task 
difficulty. Separate analyses for each of these two levels yielded more or less sinilar patterns of results.

\section{Verbal report valiaity}

Validity was tested by comparing the protocol data with the performance data, both collected in the verbalization conditions. In this comparison, the protocol data consisted of the strategy encodings given by the coders whereas the strategy encodings generated by the computer algorithm constituted the performance data.

Direct comparison of the two types of data. The strategy encodings which the two groups of coders and the computer algorithm produced were arranged in the form of contingency matrices. Separate matrices were constructed for the encodings given to the concurrent and retrospective verbalization tests. A typical example is Table 2.

Table 2. Contingency matrix based on the concurrent verbalization encodings produced by the computer algorithm and the coders of group 1. Parenthetical values are proportions.

\begin{tabular}{|c|c|cccc|}
\hline \multicolumn{2}{|c|}{} & \multicolumn{5}{c|}{ Coders } \\
\hline \multirow{4}{*}{ Strategy } & TB & HT & IN & TOTAL \\
& TB & 28 & 0 & 1 & 29 \\
& & $(0.33)$ & $(0.00)$ & $(0.01)$ & $(0.34)$ \\
& HT & 1 & 16 & 13 & 30 \\
& & $(0.01)$ & $(0.19)$ & $(0.15)$ & $(0.35)$ \\
& IN & 6 & 5 & 15 & 26 \\
& & $(0.07)$ & $(0.06)$ & $(0.18)$ & $(0.31)$ \\
& & & & & 85 \\
& TOTAL & 35 & 21 & 29 & $(1.00)$ \\
\hline
\end{tabular}

Key. TB: tracing-back; HT: hypothesis-and-test; IN: indefinite.

Expressed in terms of Cohen's kappa, the agreement between the first group of coders and the algorithrn was 0.54 for the concurrent verbalization encodings $(\mathrm{N}=85)$ and 0.53 for the retrospective verbalization encodings $(N=57)$. Similarly, the second group of coders and the algorithu gave a kappa of 0.61 for the concurrent verbalization encodings $(\mathrm{N}=80)$ and of 0.53 for the retrospective 
verbalization encodings $(\mathrm{N}=59)$. It thus appears that there was a moderate degree of agreement between the coders and the algorithm with respect to the concurrent verbalization encodings whereas with respect to the retrospective verbalization encodings the agreement was somewhat less, although it still achieved a moderate level. Comparing the two types of data with respect to experimentally induced effects. A somewhat different approach to test verbal report validity is to examine whether the protocol data reveal experimentally induced effects which correspond with those found in the performance data (see e.g. Berry and Broadbent, 1984). In the following, the results of such an approach are presented. It is important to realize that this analysis was based on the sample of 12 subjects whose verbal reports were encoded.

Table 3 presents per verbalization type and level of task

Table 3. Mean and standard deviation for each strategy-related protocol measure per verbalization type and level of task difficulty. The mean is given at the top of a cell and the corresponding standard deviation at the bottom. Each proportion has been expressed as a percentage.

\begin{tabular}{|l|llll|}
\hline \multicolumn{4}{|c|}{ Concurrent } & \multicolumn{4}{c|}{ Retrospective } \\
\hline \multicolumn{1}{|c|}{$\begin{array}{c}\text { Protocol } \\
\text { measure }\end{array}$} & \multicolumn{4}{c|}{ Task difficulty } \\
\hline \multicolumn{1}{|c|}{ Easy } & Difficult & Easy & Difficult \\
\hline $\begin{array}{l}\text { Proportion of } \\
\text { tracing-back }\end{array}$ & 25.26 & 35.05 & 44.04 & 45.46 \\
Proportion of & 31.17 & 36.77 & 30.12 & 34.17 \\
hypothesis-and-test & 53.13 & 43.20 & 30.78 & 42.52 \\
& 41.68 & 38.35 & 32.05 & 41.20 \\
$\begin{array}{l}\text { Proportion of } \\
\text { indefinite }\end{array}$ & 21.61 & 21.75 & 25.18 & 12.02 \\
\hline
\end{tabular}


difficulty the mean and standard deviation of each strategy-related protocol measure. For each of these measures, a separate MANOVA was carried out with the two within-subjects factors verbalization type (i.e. concurrent versus retrospective leaving out silence) and task difficulty. In order to guarantee a fair comparison with the performance data, exactly the same kinds of MANOVA's were conducted on the scores of the corresponding performance measures. Here too, use was made of the sample of subjects whose verbal protocols were encoded. The results of these latter analyses, which are not described in detail here, proved to be more or less in line with those reported in the section on verbal report reactivity. That is to say, for each of the three strategy-related performance measures it was found that the main and interaction effects involving verbalization type did not approach significance whereas for one of these measures, in particular for the proportion of HT, the main effect of task difficulty was significant. However, the latter effect was not significant for the proportion of TB and the proportion of IN.

The results of the MANOVA's of the protocol-based measures were as follows. For the proportion of $T B$ the main effect of task difficulty reached significance $[F(1,11)=11.48, p=0.006]$ and this effect approached significance for the proportion of $\operatorname{HT}[F(1,11)=4.32$, $p=0.0621$. When inspecting the means of these two measures given in Table 3, it can be seen that, at both levels of task difficulty, concurrent verbalization in comparison with retrospective verbalization was associated with a lower proportion of $\mathrm{TB}$ and $\mathrm{a}$ higher proportion of HT. These relationships are also illustrated in Fig. 4 and 5 where the means are plotted. It also appeared that for the proportion of HT the interaction between verbalization type and task difficulty approached significance $[F(1,11)=3.28, p=0.097]$. The nature of this interaction is clarified in Fig. 5 which shows that the difference between the two forms of verbalization with respect to the proportion of HT was quite substantial at the low level of task difficulty but almost negligible at the high level. Paired-samples $t-$ tests revealed that the difference was significant in the former case $[t(11)=2.66, p=0.022$, two-tailed] but not in the latter.

When comparing the results of the two sets of MANOVA's, it appears that the protocol data exhibit effects of verbalization type whereas the performance data do not. 


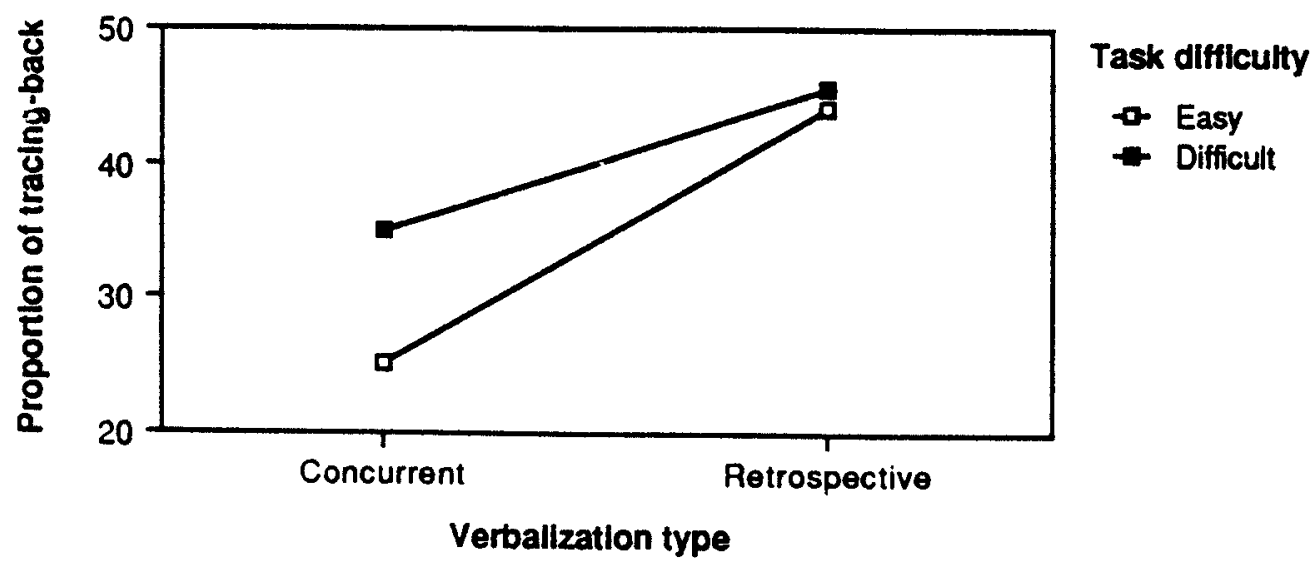

Figure 4. Mean proportion of tracing-back (in 8 ) based on the protocol data as a function of verbalization type and task difficulty.

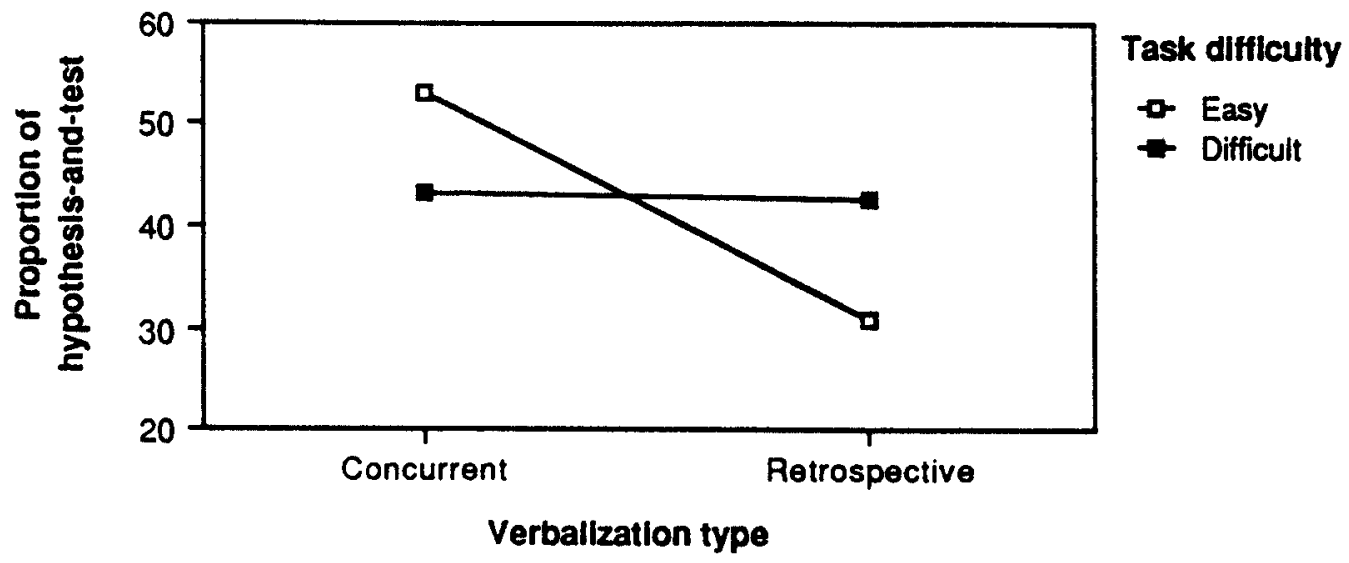

Figure 5. Mean proportion of hypothesis-and-test (in 8 ) based on the protocol data as a function of verbalization type and task defficulty. 
The results of the analyses were further examined to see which form of verbalization might be responsible for the discrepancies between the two types of data. An inspection of the means of the strategy-related performance measures (which are not reported here) pointed out that an increase in task difficulty resulted in a less thorough performance, whether verbalizing concurrently or in retrospect. In particular, the proportional use of the demanding HT strategy was considerably larger when solving easy problems than difficult problems. The mean scores of the corresponding protocol measures (Table 3) tended to show a similar task difficulty effect, that is to say for concurrent verbalization but not for retrospective verbalization. This may be interpreted to indicate that the observed differences between the performance data and the protocol data with respect to the experimentally created effects had their origin in retrospective verbalization rather than in concurrent verbalization.

\section{Discussion}

The results of the study reported here have practical, theoretical, and methodological implications.

Practical implications. The crucial point is whether we are now in the position to answer the question with which we started our study: do verbal reports possess the potential to yield a non-reactive and valid account of the cognitive processes involved in fault diagnosis? We feel that the experiment has demonstrated that the answer to this question is not a simple yes or no but requires consideration of at least one variable: the way in which the diagnostic process is accessed (i.e. by means of concurrent or retrospective verbalization). On the one hand, the findings indicate that verbalizing concurrently results in reactivity, in particular in a decrease in processing speed, whereas retrospective verbalization has no effect on performance at all. And yet, even the concurrent form of verbalization does not seem to interfere to such a degree that it is associated with more serious forms of reactivity, namely a change in accuracy and strategy. On the other hand, there are indications that the strategyrelated data obtained under concurrent verbalization are more valid than those obtained under retrospective verbalization.

It is important to realize that there are several factors restricting our ability to generalize these results. One such factor 
is the use of a very special sample of subjects, namely university students. The question can be raised whether the same results would te found for other groups of persons, e.g. operators. The concern here is that there may be significant group differences with respect to relevant subject variables, such as fluency in reporting about cognitive processes. With respect to this point, it is noteworthy that even in the relatively homogeneous sample of subjects used in the current study large individual differences in the rate and frequency of verbalization could be observed. Another factor putting restrictions on the generalizability of the results concerns the specific task conditions created in the experiment. These should certainly not be considered as representative of all the fault diagnosis situations which can be found in real life (see also Thijs, 1987). For example, in the experiment, each time a new fault-finding problem is administered which has a multi-step character. This essentially means that the problem-relevant information provided at the start defines a set of potential faults which on the basis of additionally collected information must be reduced step by step before the final diagnosis can be attempted. In practice, however, it may occur that through repeated experience with the same diagnostic situation the information obtained first can be directly linked to a particular fault, thus leading to an immediate diagnosis. Referring to the model developed by Ericsson and Simon (1984), one might argue that it is easier to report about a problem which has to be solved stepwise than about a single-step problem. This on the ground that the former problem calls for a cognitively controlled process which makes considerable use of short-term memory whereas the latter invokes an automatic recognition process.

In this context, it is interesting to note that in recent years an increasing number of studies provides several instances where, as a result of continued practice on a task, performance tends to diverge from the ability to produce a verbal report about it. It appears that such a dissociation can take various forms (Sanderson, 1989): (1) improved performance with no change in verbal reporting, (2) no change in performance with a better verbal report, and (3) improved performance with a worse report. Dissociations have been found for a variety of tasks, such as artificial grammar learning (see Reber, 1989, for a review of this research), rule learning (e.g. Lewicki et al., 1987), and dynamic systems control (e.g. Broadbent et al., 1986). 
The occurrence of a dissociation is usually interpreted to indicate that the cognitive processes used for performing the task are so different from those required for reporting about it that they cannot be accessed verbally. Unfortunately, practically all the studies presenting these indications of invalid verbal reporting adopt verbalization procedures which are not particularly appropriate, at least in the light of Ericsson and Simon's recommendations (1984). As a matter of fact, this was exactly the reason why we excluded these studies from our literature review presented in the introduction. Furthermore, a good many appear to suffer from the same methodological imperfections as those we did include. These are: failing to control for the other form of verbal report inaccuracy, i.e. reactivity, and failing to control for the operations of cognitive processing (see also Haider-Hasebrink, 1990; Sanderson, 1989 and 1990).

Notwithstanding such shortcomings, taken together the studies strongly suggest that certain aspects of task-directed cognitive processes are not accessible for a verbal report.

In view of the foregoing, it is critical that future research tries to establish whether the results of the current study are applicable to other groups of people and other types of fault diagnosis problems.

Theoretical implications. In an attempt to explain the results we obtained, we might turn to Ericsson and Simon's model of verbal reporting (1984). At the core of this model lies the assumption that verbal reporting corresponds to the articulation of information attended to in short-term memory (STM) during the course of the task to be done. So, what is needed to be able to derive non-circular explanations from the model is independent evidence as to what information is in STM at the time of the report. Unfortunately, for the fault diagnosis task used in the present study, this evidence is rather modest. Apart from the results of a somewhat subjective analysis of the basic strategies and some suggestive evidence presented in the literature (Morrison and Duncan, 1988; Toms and Patrick, 1987 and 1989), there are no really "hard" data on the specific contents of STM when performing this task. Furthermore, given the difficulties in determining on empirical grounds in what form task-relevant information resides in STM (see e.g. Anderson, 1978), such data are hard to obtain, if this is possible at all. Notwithstanding this, it may still be worthwhile to interpret our 
findings in terms of the Ericsson and Simon model, if only as a guide to further research.

Consider first the finding that concurrent verbalization increased the time to complete the task. A possible explanation for this finding is that the information being processed during task performance passes STM so quickly that it cannot be verbalized concurrently without slowing down the processing speed. This explanation, which is compatible with the Ericsson and Simon model, can be extended by assuming that the speed of information processing is inversely related to the load imposed on the limited capacity of STM. This assumption essentially means that mental activities having a slow pace require much attentional capacity while rapidly occurring activities require little or no attention (Schneider and Shiffrin, 1977). If this assumption is valid, it might be that attention-demanding cognitive processes proceed slowly enough to verbalize them completely without the need to adjust their pace. Contrastingly, cognitive processes which are relatively undemanding of attention probably speed up so greatly that in order to achieve complete verbalization they must be slowed down considerably. It can thus be argued that mental activities which require less attentional capacity will undergo a stronger slowing down when verbalizing them concurrently than mental activities which are more attention-demanding. These intuitively reasonable claims receive support from the following experimental result. Under concurrent verbalization, a higher proportional use of the less demanding tracing-back strategy was associated with a relatively larger increase in time to task completion while a higher proportional use of the more demanding hypothesis-and-test strategy was associated with a relatively smaller increase in time to task completion. Obviously, there is some empirical evidence to attribute the observed slowing down effect of concurrent verbalization to the speed of taskdirected information processing being faster than the speech rate.

In trying to explain the finding that the concurrent form of verbalization yielded data permitting a more valid identification of strategy use than retrospective verbalization, we again turn to Ericsson and Simon's model. Starting from this model, the crucial difference between the two forms of verbal reporting lies in the kind of memory from which information about the cognitive processes involved is extracted. When verbalizing concurrently, the information is directly accessible from STM while with retrospective verbalization 
the information is generally no longer available there but has to be retrieved from long-term memory (LTM). Since retrieval from LTM is fallible, retrospective verbal reports might be expected to be less valid. Note, however, that in the present study retrieval cues were administered which, according to the Ericsson and Simon model, should be particularly effective in reducing potential memory failures when verbalizing retrospectively. The question thus becomes why these cues failed in eliciting verbal reports the validity of which came up to that of the concurrent ones. One possibility is that task execution took so long that not all the information passing through STM left a retrievable trace in LTM. If so, the information contained in the retrospective reports should be less than the information content of the concurrent reports. The finding that in the task employed the frequency of retrospective verbalization was lower than the frequency of concurrent verbalization is consistent with this. Assuming that great difficulties were encountered in recovering from LTM the information held in STM during task performance, one should also allow for the possibility that the retrieval cues were used to regenerate that information by redoing the task. A verbal report based on such a regeneration process may not bear any close relationship to the actual cognitive processes.

It should be stressed that the explanations given here are merely speculative. No definite conclusions can be drawn about what caused the decrease in processing speed with concurrent verbal report production and what caused the inferior validity of retrospective verbal reporting.

Methodological implications. Since up till now it is not possible to fully specify the conditions of verbal report accuracy on the basis of theoretical notions, attempts should be undertaken to determine these empirically (Russo et al., 1989). And yet, the present study shows that an empirical assessment of verbal report accuracy is no easy enterprise either, at least when taking the approach which is normally followed. Many of the problems associated with this approach are illustrated here. For a more complete discussion of these problems, we refer to Brinkman (in press).

In the approach, non-verbal behaviors have to be recorded in order to derive the reguired set of performance data. In many settings, however, the task-directed activities are primarily cognitive and are not or hardly not accompanied with non-verbal behaviors. This problem 
becomes especially prominent when one wants to base the verbal report accuracy tests on performance data which represent the underlying operations of cognitive processing. For example, in the study presented here, a continuous record was made of the diagnostic tests the subjects successively entered while performing the fault diagnosis task selected for use. That such recordings may be unsuitable for identifying the particular strategies the subjects employed is apparent from the fact that the computer algorithm developed to make these classifications frequently failed to distinguish one strategy from another, i.e. in $40 z$ of the total number of the cases to be classified. So, for the fault diagnosis task used, there is clearly a need for a more refined measurement of observable non-verbal activities in order to allow a better identification of strategy use. Another problem with the normal approach of empirically testing verbal report accuracy is that it may be very difficult to satisfy the highly restrictive assumptions that are made about the data collected. Furthermore, verification of these assumptions may be in itself no sinecure. This problem too is the more keenly felt when basing the tests on operation-oriented performance data. In that case, one needs an adequate model of the cognitive processes used in the task being studied. For the fault diagnosis task employed in the current study, we formulated a descriptive model of strategy use and several findings can be interpreted as supporting evidence for this model, especially those indicating that the underlying assumptions of the tests on verbal report accuracy were met. Nevertheless, more research has to be done in order to establish whether the proposed model is really adequate in its present form.

Still another problem with the usual approach arises when trying to interpret the results of the data analyses. The basic idea behind the approach is that the better one set of data agrees with another set, the more accurate the verbal reporting is. This, however, does not mean that with disagreements between the two sets verbal report accuracy cannot possibly be achieved. A good many other factors may be responsible for this, e.g. adopting inadequate verbalization procedures or comparing two sets of data which capture different components of the cognitive processes supposedly referred to (see also Haider-Hasebrink, 1990; Sanderson, 1989 and 1990; white, 1988). In the present study, one should be seriously wary of the latter possibility since the performance data encompassed the actual test actions of the 
subjects while the protocol data (also) incorporated the subjects' planning and evaluative behaviors. In order to control for possible effects of such factors, one may not only need a model of the taskdirected cognitive processes but also a model specifying whether, and if so under what conditions, these processes can be reported (Bainbridge, 1979). Given that up till now a fully adequate model of verbal reporting is lacking, this requirement cannot be met so easily. In the face of the problems that arise when evaluating the quality of verbal reports according to the way it is normally done, future efforts might be directed at the development of more sophisticated approaches. 


\section{References}

Anderson, J.R. (1978). Arguments concerning representations for mental imagery. Psychological Review, 85, 249-277.

Bainbridge, L. (1979). Verbal reports as evidence of the process operator's knowledge. International Journal of Man-Machine Studies, 11, $411-436$.

Berry, D.C., and Broadbent, D.E. (1984). On the relationship between task performance and associated verbalizable knowledge. Quarterly Journal of Experimental Psychology, 36A, 209-231.

Biehal, G., and Chakravarti, D. (1989). The effects of concurrent verbalization on choice processing. Journal of Marketing Research, 26, $84-96$.

Bowers, V.A., and Snyder, H.L. (1990). Concurrent versus retrospective verbal protocol for comparing window usability. Proceedings of the Human Factors Society 34th Annual Meeting (pp. 1270-1274). Orlando, Florida: Human Factors Society.

Brinkman, J.A. (in press). Methodological problems when determining verbal protocol accuracy empirically. Paper presented at the 2nd Workshop of Cognitive Processes in Complex Tasks, Eindhoven, The Netherlands.

Broadbent, D.E., FitzGerald, P., and Broadbent, M.H.P. (1986). Implicit and explicit knowledge in the control of complex systems. British Journal of Psychology, 77, 33-50.

Cohen, J. (1960) . A coefficient of agreement for nominal scales. Educational and Psychological Measurement, 20, 37-46.

Deffner, G. (1984). Lautes Denken: Untersuchung zur oualität eines Datenerhebungsverfahrens. Frankfurt am Main: Peter Lang.

Deffner, G. (1989). Interaktion zwischen Lautem Denken, Bearbeitungsstrategien und Aufgabenmerkmalen? Eine experimentelle Prufüng des Modells von Ericsson und Simon. Sprache und Kognition, 8, $98-111$.

Deffner, G., Ericsson, K.A., and Kempkensteffen, J. (1987). Speech rate and duration of pauses during thinking aloud. Paper presented at the 28th Annual Meeting of the Psychonomic Society, Seattle.

Ericsson, K.A., and Simon, H.A. (1984). Protocol analysis: Verbal reports as data. Cambridge, Massachusetts: M.I.T. Press. 
Fidler, E.J. (1983). The reliability and validity of concurrent, retrospective, and interpretive verbal reports: An experimental study. In: P. Humphreys, O. Svenson, and A. Vari (Eds.), Analysing and aiding decision processes (pp. 429-440). Amsterdam: Elsevier Science Publishing Company.

Haider-Hasebrink, F. (1990). Explizites versus implizites wissen und Lernen. Ph.D. thesis. University of Hamburg, Germany. Heydemann, M. (1986). Der Zusammenhang zwischen Blickbewegungen und Lautem Denken bei Raven-Aufgaben. Psychologische Beiträge, 28, 7687.

Hoc, J.M., and Leplat, J. (1983). Evaluation of different modalities of verbalization in a sorting task. International Journal of ManMachine studies, 18, 283-306.

Lewicki, P., Czyzewska, M., and Hoffman, H. (1987). Unconscious acquisition of complex procedural knowledge. Journal of Experimental Psychology: Learning, Memory, and Cognition, 13, 523530 .

Mathews, R.C., Buss, R.R., Chinn, R., and Stanley, W.B. (1988). The role of explicit and implicit learning processes in concept discovery. The Quarterly Journal of Experimental Psychology, 40A, $135-165$.

McGeorge, P., and Burton, A.M. (1989). The effects of concurrent verbalization on performance in a dynamic systems task. British Journal of Psychology, 80, 455-465.

Morrison, D.L., and Duncan, K.D. (1988). Strategies and tactics in fault diagnosis. Ergonomics, 31, 761-784.

Rasmussen, J., and Rouse, W.B. (Eds.) (1981). Human detection and diagnosis of system failures. New York: Plenum Press.

Reber, A.S. (1989). Implicit learning and tacit knowledge. Journal of Experimental Psychology: General, 118, 219-235.

Rhenius, D., and Deffner, G. (1990). Evaluation of concurrent thinking aloud using eye-tracking data. Proceedings of the Human Factors Society 34 th Annual Meeting (pp. 1265-1269). Orlando, Florida: Hurnan Factors Society.

Rhenius, D., and Heydemann, M. (1984). Lautes Denken beim Bearbeiten von Raven-Aufgaben. Zeitschrift für experimentelle und angewandte Psychologie, 31, 308-327. 
Rouse, W.B. (1978). Human problem solving performance in a fault diagnosis task. IEEE Transactions on Systems, Man, and Cybernetics, SMC-8, 258-271.

Rouse, W.B., and Rouse, S.H. (1979). Measures of complexity of fault diagnosis tasks. IEEE Transactions on Systems, Man, and Cybernetics, SMC-9, 720-727.

Russo, J.E., Johnson, E.J., and Stephens, D.L. (1989). The validity of verbal protocols. Memory and Cognition, 17, 759-769.

Sanderson, P.M. (1989). Verbalizable knowledge and skilled performance: Association, dissociation and mental models. Journal of Experimental Psychology: Learning, Memory, and Cognition, 15, 729-747.

Sanderson, P.M. (1990). Implicit and explicit control of a dynamic task: Empirical and conceptual issues. Engineering Psychology Research Laboratory, Technical report EPRL-90-02, Department of Mechanical and Industrial Engineering, University of Illinois at Urbana-Champaign, Urbana, Illinois.

Schneider, W., and Shiffrin, R.M. (1977). Controlled and automatic human information processing: I. Detection, search, and attention. Psychological Review, 84, 1-66.

Schweiger, D.M. (1983). Is the simultaneous verbal protocol a viable method for studying managerial problem solving and decision making? Academy of Management Journal, 26, 185-192.

Stanley, W.B, Mathews. R.C., Buss, R.R., and Kotler-Cope, S. (1989). Insight without awareness: On the interaction of verbalization, instruction and practice in a simulated process control task. The Quarterly Journal of Experimental Psychology, 41A, 553-577.

Thijs, w. (1987). Fault management. Ph.D. thesis. University of Delft, The Netherlands.

Toms, M., and Patrick, J. (1987). Some components of fault-finding. Human Factors, 29, 587-597.

Toms, M., and Patrick, J. (1989). Components of fault-finding: Symptom interpretation. Human Factors, 31, 465-483.

White, P.A. (1988). Knowing more about what we can tell:

"Introspective access" and causal report accuracy 10 years later. British Journal of Psychology, 79, 13-45. 


\section{Appendix}

Strategy classification algorithm for the fault diagnosis task

Each test a subject attempts is classified, with the exception of the test performed on the faulty component, unless it is the first one. A test may be conducted on an input or output of a component or on the component itself. In the following, the term "feasible fault set" is used to refer to the set of components that possibly fail, given the task-relevant information obtained so far.

\section{Strategy definitions}

1. A test is an instance of tracing-back if it is carried out on an input or output of a component the output of which has recently been tested and found to be 0 . Here, "recently" refers to the last test or to a test prior to the last one if each following test has been conducted on another input of the component and has resulted in 1 . It is irrelevant whether the test has the potential to reduce the feasible fault set would its value be known.

2. A test is an instance of hypothesis-and-test if it satisfies the following two conditions:

a. it is carried out on an input or output of a component belonging to the feasible fault set;

b. it offers the possibility to remove at least one component from this set as soon as its value has become available.

\section{Basic assignment rules}

1. If a test fulfills exactly one of the two strategies as defined above, it is classified accordingly.

2. If a test fulfills neither strategy, it receives the classification indefinite.

3. If a test fulfills both strategies, it is classified as undefined. 
EINDHOVEN UNIVERSITY OF TECHNOLOGY

DEPARTMENT OF INDUSTRIAL ENGINEERING AND MANAGEMENT SCIENCE

RESEARCH REPORTS (EUT-Reports).

EUT-reports can be obtained, as long as stock permits, by writing to Eindhoven University of Technology, Library of Industrial Engineering and Management Science, P.0. Box 513, 5600 MB Eindhoven, Netherlands. The cost per delivery are HFL 3,50 plus HFL 1,50 per EUT-report. only payments by Eurocheque will be accepted.

\section{LATEST EUT-REPORTS}

EUT/BDK/50 Techniek en marketing H.w.C. van der Hart

EUT/BDK/49 Een methoden voor kosten-batenanalyse voor automatiseringsprojecten bij de overheid

M. van Genuchten, F. Heemstra, R. Kusters

EUT/BDK/48 Innoveren in technologie-gedreven ondernemingen, bedrijfskundige aspekten van de voorontwikkelfunktie w.H. Boersma

EUT/BDK/47 The creation of a research model for estimation

EUT/BDK/46 Het 80 flat square project; Een case studie als

M. Howard

aangrijpingspunt voor lerend innoveren J.I.M. Halman,

J.A. Keizer

EUT/BDK/45 Interface design for process control tasks

T.W. van der Schaaf

EUT/BDK/44 Afzetfinanciering S.G. Santema

EUT/BDK/43 Het gebruik van natte (industriële) bijproducten in de varkenshouderij; Een verkenning van de Nederlandse situatie Mat. L.M. Stoop

EUT/BDK/42 An integral approach to safety management T.W. van der Schaaf EUT/BDK/41 De produktie van varkensvlees; Een integrale ketenbenadering Deelrapport 1: Enkele modellen voor de varkenshouderij A.J.D. Lambert

EUT/BDK/40 Informatievoorziening ten behoeve van klantenorder-acceptatie; een eerste verkenning F.J. Faszbender

EUT/BDK/39 A bibliography of the classical sociotechnical systems paradigm F.M. van Eijnatten

EUT/BDK/38 Meten van kwaliteit van Nederlandse instrumentatie op basis van ontwerpgerichte toepassingsaspekten F.M. van Eijnatten

EUT/BDK/37 De toepassing van vaardigheden bij de specificatie van het bewerkingsvoorschrift D.R. Muntslag

EUT/BDK/36 Selection of Software Cost Estimation Packages F.J. Heemstra, M.J.I.M. van Genuchten, R.J. Kusters

EUT/BDK/35 Zoekboek Arbeidssysteemstructurering: een overzicht van criteria voor autonome groepen P.J.M. Berger,

R.E.F. van den Heuvel, M.H.M. Rietrae, P.G.M. Simons, onder redactie van F.M. van Eijnatten

EUT/BDK/34 Organisatie van produktinnovatieprocessen in middelgrote ondernemingen; een verslag van zes case-studies in de kunststofindustrie H.C. van der Hek-de Keyser, c.C. Krijger

EUT/BDK/33 Innovatie gedefinieerd; een analyse en een voorstel B.J.G. van der Kooij

EUT/BDK/32 A conceptual Framework for Software Cost Control and Estimation F.J. Heemstra, R.J. Kusters

EUT/BDK/31 Het verband tussen afval-arme methoden en energiegebruik bij de winning van minerale grondstoffen A.J.D. Lambert, J.C.M. Marijnissen 